\title{
Cuidando do cuidador: Perspectiva de atuação psicológica em uma casa de apoio
}

\author{
Taking care of the caregiver: Perspective of psychological \\ performance in a specific support house
}

\begin{abstract}
Adriana Soczek Sampaio
Psicóloga da Associação Paranaense de Apoio à Criança com Neoplasia (APACN), Curitiba, PR - Brasil, e-mail: psicologia@apacn.org.br
\end{abstract}

\section{Resumo}

O paciente oncológico pediátrico atendido em uma casa de apoio está, por necessidade do seu tratamento médico, afastado do seu ambiente familiar, por tempo indeterminado e submetido a procedimentos invasivos numa rotina desgastante. Nomear-se ou ser nomeado "cuidador" desse paciente e levar a termo essa tarefa não é uma atividade fácil e nem livre de sentimentos como incerteza, medo, angústia e dor. No entanto, em geral, o cuidador foca o paciente e presta menor atenção em si, tendo-se, assim, espaço para este adoecer física, psíquica e emocionalmente. Logo, a criação do grupo de apoio visou a poder oferecer aos cuidadores a possibilidade de troca de informações, de reflexão sobre si mesmos e sobre os assuntos de seu interesse. Foram realizados 12 encontros, com uma média de 12 participantes por encontro e com duração aproximada de uma hora e meia. Em alguns encontros, utilizou-se algum material de apoio, como música ou leitura de texto, mas o essencial era a conversa e a troca de experiências entre os cuidadores, sendo a participação da psicóloga restrita ao de mediadora da atividade. Em uma análise subjetiva e não quantitativa, concluiu-se que o trabalho realizado atingiu seu objetivo pelo relato posterior de alguns participantes, porque, sobretudo, observaram-se cuidadores voltando-se aos seus próprios cuidados. Alguns pontos negativos também foram observados e se encontram na conclusão deste artigo.

Palavras-chave: Cuidador. Grupo de apoio. Casa de apoio. 


\begin{abstract}
The pediatric oncology patient accomodated in a support house is, for necessity of its medical treatment, distant of your familiar habitat, for indeterminate time and submitted for invasibles procedures in a tiresome routine. Entitling oneself or being constituted caregiver for this patient and execute this task is not an early activity nor free of feelings like uncertainty, fear, distress and pain. However, in general, caregiver take priority about the patient and take minor attention in yourself, emerging opportunity for caregiver to become physically, psychologically and emotionally sick. At once, the creation of a support group has intended to offer to caregivers the possibility to change information, of reflections about yourselves and about the subjects of your interesting. It were performed 12 encounters, with a mean of 12 members per encounter with one hour and thirty minutes of duration every encounter. In some encounters it was used some support material, as music or texts, but the essential was the conversation and experiences changed between caregivers, with the psychological participation to go between the members. In a subjective and non-quantitative analyses, it is possible to conclude that the job reached its target by the backside report of some caregivers, because of, however, much caregivers focused for their own care too. Some negative points were observed too and are in the conclusion of this article.
\end{abstract}

Keywords: Language. Acquisition. Stimuli.[\#]

\section{Introduçáo}

A Associação Paranaense de Apoio à Criança com Neoplasia (APACN) foi fundada em 21 de outubro de 1983 e objetiva, desde sua fundação, a humanização do tratamento do câncer infanto-juvenil. Para isso, oferece na sua casa de apoio todo o amparo necessário para crianças e adolescentes com seus acompanhantes ${ }^{1}$, vindos de todo o Brasil e também de países vizinhos, em busca de tratamento para doenças hemato-oncológicas na cidade de Curitiba (Paraná).

Logo, as crianças, os adolescentes e seus cuidadores recebidos na casa de apoio são, pela necessidade do tratamento, afastados do convívio familiar, da rotina e do ambiente social que lhe são peculiares e são inseridos em um novo contexto (hospital, casa de apoio, outra cidade) com base no diagnóstico de uma doença crônica (câncer, doenças hematológicas e/ ou outras doenças com indicativo de transplante de medula óssea-TMO) ou na busca desse diagnóstico, de tratamento prolongado e invasivo, e de prognóstico, muitas vezes, ruim. Objetivando humanizar esse período de vida do paciente e de seu cuidador é que a APACN oferece uma série de serviços. Entre estes, há o acompanhamento psicológico tanto para os pacientes quanto para os cuidadores.

Cuidar de uma pessoa doente já não é rotina fácil, ainda mais quando o paciente em questão é o próprio filho, criança ou adolescente, com "um futuro pela frente". Outro complicador é o fato de não se tratar, nesse caso, de uma doença de breve duração e de fácil tratamento, mas sim de uma doença maligna como o câncer, ou não maligna como as aplasias de medula, mas que pode necessitar de transplante de medula óssea (TMO), de tratamento invasivo, sendo um processo desgastante tanto para o paciente quanto para seu cuidador. Apesar de os índices atuais de cura do câncer infantil serem de cerca de $70 \%$ quando detectados precocemente e adequadamente tratados (INCA, 2007), o impacto desse diagnóstico sobre a família é bastante forte, havendo, como refere Ortiz (2003, p. 31), um descompasso entre a concepção médica e a compreensão coletiva do câncer. Afirma: "para a maioria das pessoas, câncer é sinônimo de morte". Com esse diagnóstico médico vem junto uma mescla de sentimentos em todos os familiares do núcleo próximo à criança que vão desde a incredulidade e negação ("isto não pode estar acontecendo") até o desespero ("se ele morrer minha vida acaba") ${ }^{2}$.

\footnotetext{
1 Tratado, daqui para frente, por "cuidador".

2 Frases ilustrativas, adaptadas de falas diversas de diferentes cuidadores.
} 
No caso de pacientes adultos, o cuidador geralmente é o cônjuge ou os filhos adultos. No caso do paciente ser uma criança ou um adolescente, geralmente o cuidador principal é a mãe, em menor número de vezes o pai ou outro parente responsável (irmãos, avós, tios). É bastante fácil de compreender essa lógica, já que geralmente o pai é o provedor principal da família e é quem necessita ficar em casa para a manutenção e sustento de todos. Quando há outros filhos, esses ficam em casa com o pai, sendo monitorados pelos irmãos mais velhos, por demais parentes ou vizinhos durante a jornada de trabalho paterna. Seguindo essa linha seletiva, claro está que a mãe, cuidador principal que deixa sua casa, seu esposo e os outros filhos, enfrenta uma dupla tarefa: preocupar-se a distância com os que ficam e com o diagnóstico/tratamento/saúde daquele que acompanha.

Valle (1997, p. 117), com propriedade, denomina esse momento como um "tempo de catástrofe, de incertezas, de sentimentos de angústia diante da possibilidade de morte". Quando é necessário, como visto nos casos daAPACN, que o cuidador "abandone" temporariamente, mas por tempo indeterminado, sua casa, seus outros filhos (às vezes ainda bebês) e seu marido/companheiro e siga para outra cidade, muitas vezes distante e desconhecida, para o tratamento do filho, há que se considerar que esse é mais um momento gerador de angústia perante os desconhecidos que se há de enfrentar (nova cidade, tratamento, reações adversas, etc).

No núcleo familiar se dá uma espécie de reestruturação familiar, com uma redefinição de papéis, visto que o pai, que ficou em casa, passa à dupla jornada de provedor da família e de atuante na rotina dos cuidados do lar e dos filhos. Ou esse lugar é ocupado por um(a) filho(a) mais velho. Há casos também em que, pela distância da díade paciente-cuidador por um período de tempo longo, a relação familiar é desestruturada a ponto de haverem rupturas como separações do casal e mesmo a busca por uma terceira pessoa pelo genitor que ficou em casa.

Considerando-se esse quadro delineado, somado à história de vida de cada cuidador (suporte social disponível, manejo de situações de estresse, história anterior de doenças psíquicas como depressão e ansiedade, entre outros), estes acabam expostos à maior probabilidade de adoecimento psicológico, mesmo porque a preocupação com o filho é grande o suficiente para abarcar quase que inteiramente seu foco de atenção, e muitos cuidadores deixam de cuidar de si mesmos, abrindo espaço para o adoecer físico, psíquico e emocional. Afirmam autores como Manne et al. (2007) que o período do TMO dos filhos é facilitador para o aparecimento de sintomas como transtorno depressivo, ansiedade e transtorno de estresse pós-traumático, especialmente verificado em seus estudos, em mães que assumem o papel de cuidador principal. Mesmo não possuindo dados empíricos, pode-se arriscar a dizer, pela observação da prática clínica com essa população, que também cuidadores de filhos com outros tipos de tratamento, como cirurgia, quimioterapia e radioterapia, também passam por período de estresse e, não raramente, externam sintomas de ansiedade.

Tendo em vista todas essas situações pelas quais os cuidadores passam, respeitadas as suas particularidades, o serviço de psicologia decidiu realizar um trabalho com essa clientela, entre outubro de 2005 a maio de 2006, visando ao cuidado daqueles que sempre estão cuidando ao proporcionar um espaço para pensarem em si mesmos, em suas necessidades e na troca de experiências, sendo, assim, um trabalho preventivo e de suporte.

\section{Objetivo}

A criação do grupo de apoio visou a oferecer um momento aos cuidadores para eles mesmos, para refletir sobre si, os cuidados que estão tendo consigo mesmos ou que estão deixando de ter, bem como favorecer um espaço para a troca de experiências de manejos de situações pelas quais estão passando, guardando sempre semelhanças entre si. Objetivou também sinalizar aos cuidadores que é necessário ter espaço e tempo também para si, posto que só alguém que está bem consegue cuidar de outra pessoa. Assim, o objetivo geral do grupo foi a troca de ideias, sentimentos, experiências e informações sobre os mais variados temas, desde que de interesse do grupo e por este escolhido, em um momento só dos cuidadores.

\section{Metodologia}

Os encontros do grupo ocorreram quinzenalmente, com duração aproximada de uma hora e 30 minutos. Os temas eram escolhidos pelos 
participantes, do primeiro para o encontro seguinte e assim sucessivamente. A atuação da psicóloga foi de mediadora nos encontros, com participação com vista a fornecer informações técnicas, orientar a discussão dos participantes e aplicar algumas dinâmicas ao final de alguns dos encontros. Todos os cuidadores hospedados na casa eram convidados a participar, não havendo obrigatoriedade de participação.

Ao longo dos encontros, os temas escolhidos e trabalhados com o grupo foram: limites para os filhos, doença dos filhos, depressão, cuidados com a saúde, atividade física e alimentação, família, educação e filhos, medicina e postura médica, e amizade.
Em alguns encontros foi levado material escrito para ser lido, como disposto no Quadro 1.

No primeiro encontro, utilizou-se o CD Melodia das águas ${ }^{3}$ para relaxamento induzido, de abandono de pensamentos e sentimentos negativos; no segundo, foi realizado também um relaxamento induzido; no terceiro encontro, com a música Paciência ${ }^{4}$, foi feita uma dinâmica do tesouro; no sexto, usou-se a música Família para abertura das discussões sobre o tema e ao final uma dinâmica do abraço; e no décimo segundo encontro usou-se um desenho animado do Ursinho Pooh ${ }^{6}$ referente ao tema da amizade.

Quadro 1 - Material textual trabalhado nos encontros

\begin{tabular}{|c|c|c|}
\hline $\mathbf{N}^{\circ}$ do encontro & Tema & Material textual \\
\hline $1^{\mathrm{o}}$ & Limites para os filhos & $\begin{array}{l}\text { Texto: Mães más } \\
\text { Autor: Carlos Hecktheuer }\end{array}$ \\
\hline $2^{\circ}$ & Doença dos filhos & $\begin{array}{l}\text { Texto: A menina da árvore } \\
\text { Autor: Eva Furnari, recontada por May Shuravel }\end{array}$ \\
\hline $9^{\circ}$ & Doença dos filhos & Texto: Madre Tereza de Calcutá (sem título conhecido) \\
\hline $10^{\circ}$ & Medicina e postura médica & Texto: Salvem os doutores e a medicina de hoje (autor desconhecido) \\
\hline $11^{\circ}$ & $\begin{array}{l}\text { Medicina e postura médica } \\
\text { (continuação) }\end{array}$ & Texto: Mensagem pelo dia das mães (mensagem recebida por email) \\
\hline
\end{tabular}

Fonte: Dados da pesquisa.

\section{Resultados e discussáo}

Nesses 12 encontros teve-se a participação de 58 cuidadores em um total de 147 participações, já que alguns cuidadores participaram mais de uma vez. É importante salientar que o número de participações sempre estava condicionado ao número de cuidadores hospedados em cada data de encontro, e essa hospedagem estava diretamente ligada ao tratamento da criança, posto que este define o período de permanência em Curitiba, na casa de apoio ou no hospital, ou libera o cuidador e o paciente para passarem alguns dias em casa.
No Tabela 1 são descritos os temas discutidos em cada encontro, bem como o número de participantes em cada um deles.

No primeiro encontro foi lido o texto Mães más, que sugere uma reflexão interessante sobre todos os "nãos" ditos por uma mãe, bem como sobre os pedidos feitos aos filhos, tendo como consequência o desenvolvimento deles com uma postura moral e social positiva, deixando evidente que é sinal de amor, sim, estabelecer e cobrar limites dos filhos. Esse texto abriu a discussão sobre o tema, posto que muitos cuidadores possuem dificuldade de dizer não aos desejos dos filhos, especialmente após o diagnóstico

\footnotetext{
3 CD Melodia das Águas - Azul Music - coletânea produzida por Corciolli, 2004.

4 Música de Dudu Falcão e Lenine. Ed. EMG music/Mameluco (Trama Music). Faixa 4 do CD Vila Madalena.

5 Música de Arnaldo Antunes e Tony Belotto. Faixa 4 do CD Titãs Acústico MTV, 1997.

${ }^{6}$ DVD da Disney.
} 
Tabela 1 - Temas dos encontros e número de participações

\begin{tabular}{clc}
\hline $\mathbf{N}^{\circ}$ do encontro & \multicolumn{1}{c}{ Tema } & $\mathbf{N}^{\mathbf{o}}$ de participantes \\
\hline $1^{\circ}$ & Limites para os filhos & 8 \\
$2^{\circ}$ & Doença dos filhos & 12 \\
$3^{\circ}$ & Depressão & 10 \\
$4^{\circ}$ & Cuidados com a saúde & 11 \\
$5^{\circ}$ & Atividade física e alimentação & 10 \\
$6^{\circ}$ & Família & 20 \\
$7^{\circ}$ & Óbito de paciente da casa ${ }^{7}$ & 16 \\
$8^{\circ}$ & Educação e filhos & 15 \\
$9^{\circ}$ & Doença dos filhos & 8 \\
$10^{\circ}$ & Medicina e postura médica & 10 \\
$11^{\circ}$ & Medicina e postura médica (continuação) & 10 \\
$12^{\circ}$ & Amizade & 18 \\
\hline
\end{tabular}

Fonte: Dados da pesquisa.

de câncer. Alguns cuidadores contaram sobre suas relações saudáveis com seus filhos e como conduzem os limites para que o convívio seja tranquilo. Outros se sentiram à vontade para expor suas dificuldades no manejo de limites e de se fazerem atendidos por seus filhos.

Houve entre ambos os grupos troca de experiências sobre como manejar as situações de maneira a melhorar a interação mãe-filhos. A troca favoreceu o aprendizado de uns a partir da experiência de outros; e aqueles que conduzem com êxito a relação com os filhos puderam compreender que estão no caminho certo quanto à educação destes.

Nos encontros sobre a doença dos filhos ${ }^{8}$, os cuidadores puderam trocar experiências e informações que adquiriram durante o tratamento de seus filhos, assim como a psicóloga trouxe um resumo de cada uma das doenças, em linguagem leiga, retirado esse material de textos técnicos e sites confiáveis sobre o assunto. Frisou-se que cada situação é singular e deve-se cuidar ao fazer generalizações, pois diagnósticos semelhantes não querem dizer tratamento e prognóstico semelhantes. Essa troca foi bastante rica, pois cuidadores com filhos em início de tratamento puderam sanar dúvidas e minimizar alguns medos do que desconheciam por meio do relato de outros cuidadores, havendo também espaço para a expressão de todos aqueles que desejaram contribuir com o grupo.

No encontro sobre depressão, a psicóloga foi solicitada a participar ativamente, explicando sobre sintomas e tratamento. Um dos cuidadores disse que, sempre quando ouvia a palavra "depressão", pensava em uma panela "de pressão”. A colocação foi acolhida e foram trabalhadas ambas as expressões, termo médico e visão leiga, fazendo com que os participantes, perante o que já havia sido explicado, definissem a sua noção do que é adoecer de depressão, desmistificando a doença como por vezes pensada como preguiça e/ou falta de vontade/iniciativa daquele que adoece. Mais uma vez alguns cuidadores manifestaram-se contando

\footnotetext{
7 O assunto deste encontro era para ser Educação de filhos, mas por consenso dos participantes, falou-se sobre morte já que uma adolescente da casa havia falecido e sua mãe estava indo embora para sua cidade.

8 Foram feitos dois encontros com o mesmo tema a pedido de cuidadores.
} 
recortes de suas histórias nas quais tiveram sensações, pensamentos e atitudes condizentes com depressão e como fizeram para melhorar e transpor esse momento em suas vidas.

No encontro sobre cuidados com a saúde, a ênfase recaiu sobre doenças sexualmente transmissíveis (DSTs), controle da natalidade, exames preventivos de câncer de mama e de colo do útero e necessidade de fazê-los no tempo correto, já que são formas de câncer para os quais há possibilidade de cuidados preventivos e detecção precoce. Após o debate sobre o tema, a psicóloga constatou que um número significativo de acompanhantes estava com o exame preventivo para câncer de colo do útero atrasado há pelo menos um ano e meio ou dois, sendo que havia uma que nunca havia feito. Apesar de esse tipo de atividade ser realizada, geralmente, pelo Serviço Social, a psicóloga aproveitou o contato que tinha com uma Unidade de Saúde próxima à instituição e agendou exames para as mães que precisavam e queriam. Procedeu também na distribuição de preservativos a todos os cuidadores que desejaram, doados pela Unidade de Saúde, quando cada um estava de retorno para sua casa, sendo que o pedido era feito com vistas a garantir o controle da natalidade, segundo relatado por cada cuidador. O tema contribuiu para a conscientização de cada um dos cuidadores em relação aos cuidados com saúde, DSTs e planejamento familiar a ser discutido com seus cônjuges e companheiros.

A partir da discussão sobre os cuidados com a alimentação e sobre a atividade física, cuidadores passaram a se interessar mais pelo tema e pesquisar sobre alimentação saudável, bem como adotar a prática diária de caminhadas que traz benefícios à saúde física e mental. Conforme pedido pelo grupo, foi entrado em contato com o setor de voluntariado e foi solicitado um voluntário professor de educação física para orientar aqueles cuidadores que queriam realizar alguma atividade física, em um espaço com alguns equipamentos obtidos em doação (esteira, bicicleta ergométrica, entre outros). $\mathrm{O}$ pedido foi atendido e os cuidadores que desejaram passaram a ter orientação para realizar algumas atividades físicas enquanto hospedados na instituição.

O tema sobre a família trouxe histórias bastante divergentes, sendo que foi possível delinear famílias bastante prestativas e auxiliadoras do núcleo mais diretamente envolvido com a doença da criança/adolescente, até famílias desestruturadas, sem vínculo suficiente para permitir um auxílio, ou sem interesse, ainda que mínimo, pela díade em tratamento em Curitiba. Nesse encontro observou-se que muitos cuidadores refletiram sobre o que estão passando e decidiram, se sem o apoio de familiares, lutar pelo filho com o apoio apenas das pessoas que se mostravam legitimamente interessadas. Importante frisar que também se observou certo pesar pela constatação, de alguns cuidadores, de que estavam sozinhos nessa luta pela recuperação do filho. Porém, o grupo ofereceu apoio mútuo entre os participantes, o que trouxe um amparo a todos, especialmente àqueles que se sentem sozinhos nessa empreitada.

$\mathrm{Na}$ data do sétimo encontro, uma adolescente havia falecido naquela noite e no horário do encontro a mãe enlutada foi até o grupo despedir-se para retornar para sua casa. Comovidos, os cuidadores quiseram deixar o tema escolhido para falar sobre a morte. Num grupo em que as histórias se assemelham, a dor de um se torna a dor de todos porque o medo de perder o filho é grandemente aumentado quando há um óbito entre os conhecidos. Segundo Sampaio e Lohr (2008, p. 60), momentos de perda e luto "são momentos com forte pressão emocional, em que o suporte psicoemocional tanto à família que perdeu uma criança como aos demais residentes na casa, é fundamental, uma vez que a perda se torna, em termos, a perda de todos". Os cuidadores expressaram pesar, dor, medo, indignação pela morte da adolescente, morte esta considerada por eles como repentina e com incredulidade ("parece mentira, há alguns dias ela estava aquil"). $\mathrm{Na}$ despedida da mãe enlutada, cada cuidador presente abraçou e se despediu da mãe que retornava à sua casa, dizendo palavras que visavam a dar apoio, ao mesmo tempo em que precisavam ser amparadas e ouvidas em sua dor.

O encontro sobre educação e filhos diferiu do que falou sobre limites porque teve um enfoque mais amplo, contemplando também o uso de reforçadores positivos no cotidiano de cada família, como a expressão de carinho e afeto, e as atividades interativas entre pais-filhos e entre irmãos. Os cuidadores também discutiram o uso de medidas coercitivas, nos momentos por cada um considerados oportunos, para auxiliar na compreensão de regras e obediência em geral. Tais medidas são, basicamente, o uso de castigos, uma vez que o bater no filho foi considerado errado como metodologia de educação pela maioria dos cuidadores, acrescido do fato de 
que o estado de saúde em que a criança se encontra inibe esse tipo de coerção nos cuidadores em geral.

Nos dois encontros em que o tema foi a medicina e a postura médica, o foco da discussão recaiu sobre a relação entre cuidador e paciente com a equipe médica responsável pelo tratamento deste. Houve a troca de experiências entre cuidadores referente a como foram informados sobre diagnóstico inicial, tratamento, recidiva, entre outros assuntos, havendo uma variedade de maneiras nas quais a informação chegou até o cuidador. Falou-se também da falta de informação que, por vezes, ocorre por falha da equipe no repasse, mas também por falta de o cuidador, como maior interessado, questionar a equipe a respeito de suas dúvidas e curiosidades. Houve cuidadores que, refletindo e discutindo o tema, concluíram que têm o direito de fazer mais perguntas à equipe para sanar dúvidas que surjam durante qualquer momento do tratamento do paciente, descoberta essa apoiada pela psicóloga, já que o esclarecimento é uma medida eficaz para a adesão e a diminuição de sentimentos como medo e angústia.

Para o último encontro, o tema escolhido foi amizade, assistindo-se à parte de um desenho animado sobre o tema para a introdução do assunto. Por ser vasto, esse tema trouxe uma séria de discussões entre os cuidadores, mas a ênfase recaiu sobre a amizade que eles consideram necessária haver entre eles como hóspedes da casa de apoio e pessoas passando por situação semelhante, que é a doença/tratamento do filho longe de casa. Foi debatida também a falta de companheirismo entre o grupo em alguns momentos e a cisão em grupos menores, sendo compreendido, ao final, que as dificuldades acabam motivando maior ou menor proximidade entre as pessoas, de acordo com cada um.

Após os 12 encontros, todos os cuidadores participantes foram solicitados a daruma pontuação de zero a dez ao trabalho de grupo realizado, sendo que de zero a três a resposta era considerada como "insatisfeito com o trabalho"; de quatro a sete como "satisfeito com o trabalho"; e de oito a dez como "muito satisfeito com o trabalho". Mesmo tendo participado mais de uma vez, cada cuidador deu apenas uma nota, visto que a intenção era qualificar o trabalho como um todo e não cada encontro individualmente. Após a soma de todas as notas dadas e feita a média aritmética pelo número de notas atribuídas (que corresponde ao número de cuidadores participantes), encontrou-se um total de 8,6 de pontuação para o trabalho realizado pela psicologia para os cuidadores hospedados na casa de apoio da APACN. Isso quantifica o trabalho como tendo sido mais que satisfatório para a maioria dos participantes, superando as expectativas do próprio setor de psicologia.

\section{Conclusáo}

É importante salientar que, apesar do índice superior alcançado na qualificação dos cuidadores, dificuldades existiram também neste trabalho. Conforme conversado informalmente com psicólogas de outras duas casas de apoio, nem sempre os cuidadores têm interesse de ir para os encontros realizados ou mesmo falar de si para os outros. Em alguns encontros foi repetido o convite, por sistema de som, para o início das atividades, não no sentido de obrigatoriedade, mas no sentido de convite a um momento para si mesmos. Talvez outro estudo mais atento e detalhado sobre esse aspecto possa ser realizado no sentido de discutir se o cuidador, ao entregar-se aos cuidados do outro, não sente necessidade de cuidar de si.

Outro aspecto observado foi que, durante os encontros, por vezes, cuidadores falavam em simultaneidade, atrapalhando o grupo e favorecendo a dispersão de todos. Mediar a interlocução, assim, nem sempre se fazia tarefa fácil e o ouvir acabava tendo algumas perdas de trechos de relatos, mas sem perdas significativas no contexto geral.

Os temas foram relevantes para os participantes como um todo, sendo que um bom número de cuidadores sempre estava disposto a contribuir nas discussões.

Como fechamento do trabalho realizado, pode-se dizer que ele cumpriu com a função que se propôs alcançar, que era favorecer justamente a troca de experiências de vida entre os cuidadores em um momento/espaço destinado somente a eles, sabedores de que havia a preocupação da instituição como um todo em também prestar cuidados a eles, tantas vezes deixados em segundo plano até por eles mesmos. Logo, cuidar do cuidador é também tarefa do profissional de saúde no sentido da promoção de um cuidador saudável para si e pelo que isso representa em relação ao paciente atendido, como garantia da adesão e da continuação do tratamento necessário com qualidade de atuação e interação com esse paciente. 


\section{Referências}

Instituto Nacional do Câncer - INCA. (2007). Particularidades do câncer infantil. Recuperado em 10 ago. 2007, em http://www.inca.gov.br/conteudo_view.asp?id $=343$

Lenini (Interp). Paciência. Música de Dudu Falcão e Lenine. Rio de Janeiro: EMG music/Mameluco (Trama Music), 2007. Faixa 4 do CD Vila Madalena.

Manne, S., DuHamel, K., \& Ostroff, J., et al. (2004). Anxiety, depressive, and posttraumatic stress disorders among mothers of pediatric survivors of hematopoietic stem cell transplantation. Pediatrics, 113(6), 1700-1708. Recuperado em 2 jul. 2007, em www.pediatrics.org

Melodia das Águas. Azul Music. 2004. 1 CD coletânea produzida por Corciolli.

Ortiz, M. C. M. (2003). Falando de câncer e de mães. In M. C. M. Ortiz. À margem do leito: A mãe e o câncer infantil. São Paulo: Arte e Ciência.

Sampaio, A. S., \& Löhr, S. S. (2008). Atuação em casas de apoio: Pensando o papel da psicologia e construindo novos caminhos. RUBS, 1(3), 52-60.

Titãs (Interp.). Famílias. Música de Arnaldo Antunes e Tony Belotto. Rio de Janeiro: Unidades Móveis Nas Nuvens e Solo, 1997. Faixa 4 do CD Titãs Acústico MTV.

Valle, E. R. M. (1997). Câncer infantil, compreender e agir. Campinas: Editorial Psy.

Recebido: 09/03/2010

Received: 03/09/2010

Aprovado: 19/05/2010

Approved: 05/19/2010 